\title{
O Mecanismo da Mais Valia Relativa
}

\author{
Francisco Paulo Cipolla \\ Professor - Universidade Federal do Paraná \\ Endereço: Av. Prefeito Lothário Meissner, 632 - Campus III - Jardim Botânico \\ Curitiba - PR - Brasil - CEP: 80210-170 - E-mail: cipolla@ufpr.br \\ Recebido em 14 de agosto de 2012. Aceito em 29 de novembro de 2013.
}

\begin{abstract}
Resumo
Em discussão recente com Fine (2009), Lebowitz $(2003,2010)$ argumenta que a teoria da mais valia relativa de Marx é inadequada porque toma a cesta de meios de consumo necessários à reprodução da força de trabalho como fixa. Uma vez abandonada essa hipótese, se o salário nominal não se reduz, o aumento da produtividade se traduz apenas numa ampliação do consumo dos trabalhadores. Na sua opinião, é necessário considerar que o progresso técnico tem não só como objetivo único diminuir o valor das mercadorias, mas também o de enfraquecer a capacidade de resistência da classe como um todo. Somente a compreensão de que o progresso técnico é uma arma da luta de classe torna possível conceber a redução dos salários nominais como processo simultâneo ao barateamento das mercadorias. Este artigo procura explorar possibilidades alternativas para a efetivação da mais valia relativa independentemente da redução dos salários monetários. Para tanto, analisam-se os possíveis efeitos do aumento da produtividade na produção de ouro, assim como os possíveis efeitos de desvalorizações do padrão de preço.
\end{abstract}

\section{Palavras-Chave}

mais valia relativa, salários nominais, produtividade do trabalho

\begin{abstract}
Marx's theory of relative surplus value has been recently questioned by Michael Lebowitz (2003, 2010). According to him the value of labor power cannot be determined by the value of a given set of consumption goods. He argues that this procedure fails to explain relative surplus value when money wages fail to fall. Unless productivity is able to explain both the cheapening of commodities and the weakening of the working class, the theory of relative surplus value is incomplete for it is unable to explain the reduction in money wages. This article explores the possible effects of changing productivity in gold production, a factor that Marx left out of the analysis in order to emphasize the necessary reduction in money wages when the value of gold is given. It is shown that relative surplus value can come about quite independently of any reduction in money wages.
\end{abstract}

\section{Keywords}

relative surplus value, nominal wages, productivity of labor

\section{JEL Classification}

B51

- Gostaria de agradecer as excelentes observações de parecerista anônimo, o qual, no entanto, eximo de eventuais defeitos remanescentes. 


\section{Introdução}

Como se sabe, Marx apresenta a teoria da mais valia relativa tomando como dadas as necessidades de consumo da força de trabalho, ou seja, partindo da hipótese de uma cesta de consumo conhecida e fixa. Como se discutirá adiante, esse procedimento é necessário para estabelecer a origem da mais valia relativa.

Quando aumenta a produtividade e diminui o valor das mercadorias daquela cesta, aumenta pro rata o valor excedente adicionado na jornada, isto é, aumenta a mais valia de forma relativa. Segundo Lebowitz $(2003,2010)$, esse raciocínio implica supor que o salário nominal se adapta ao novo valor da cesta de consumo. Uma vez retirada a hipótese de uma cesta de consumo fixa, a manutenção dos mesmos salários nominais implica que o valor da força de trabalho se mantém constante e não pode haver mais valia relativa. Ao contrário, seriam os trabalhadores os beneficiários do aumento da produtividade, uma vez que sua cesta de consumo teria aumentado.

Para que haja mais valia relativa é preciso que os salários nominais caiam. É necessário, portanto, que se incorpore na análise o elemento capaz de promover a redução dos salários nominais. Para que caia o salário nominal é preciso que o aumento da produtividade traga consigo um elemento de enfraquecimento da coesão da classe trabalhadora. Assim, uma vez retirada a hipótese de cesta fixa, argumenta Lebowitz, é necessário mostrar que o progresso técnico comporta algum mecanismo que fragilize os trabalhadores e conduza à redução dos salários nominais, redução essa necessária para permitir a existência de mais valia relativa.

Por isso ele introduz a luta de classe como parte da análise da mais valia relativa. A luta de classe é introduzida na análise através do conceito de grau de divisão (degree of separation) entre os trabalhadores. O grau de divisão é a variável que permite transformar o aumento da produtividade em mais valia relativa. Lebowitz procura mostrar que há uma conexão necessária entre o aumento de produtividade e o aumento do grau de divisão entre os trabalhadores, conexão sem a qual a mais valia relativa seria contingente e não necessária. Mas como? Uma vez que o enfraquecimento do grau de coesão dos trabalhadores é condição da mais valia relativa, o aumento da produtividade deve se manifestar ao mesmo tempo como força 
desagregadora da capacidade de defesa dos trabalhadores enquanto classe. Como exemplo, ele cita a introdução de máquinas analisada por Marx no capítulo sobre a Maquinaria e Grande Indústria e seus efeitos em termos de aumento da concorrência entre trabalhadores e a consequente diminuição dos salários (2010, p.146). De modo geral, pode-se dizer que toda a seção 4 sobre $A$ Produção de Mais Valia Relativa descreve o processo de simplificação do trabalho e, como tal, apresenta a forma histórica do aumento do número de trabalhadores disponíveis para o capital no bojo da qual os trabalhadores lutam uns contra os outros pelo emprego, isto é, a forma empírica do grau de divisão da classe trabalhadora.

Desse modo, o grau de divisão, segundo Lebowitz, faz parte do nível de análise da mais valia relativa e, portanto, do conceito de capital em geral, pois sem o aumento do grau de divisão os incrementos de produtividade não poderiam se traduzir em mais valia relativa. Assim, a tendência imanente do capital a produzir mais valia relativa só pode se efetivar através do enfraquecimento da coesão de classe dos trabalhadores.

Lebowitz se baseia na noção de que o progresso técnico tem não só como único objetivo diminuir o valor das mercadorias, mas também o de aumentar o grau de divisão entre os trabalhadores, de forma que se constitui num mecanismo da luta de classe através do qual o capital consegue simultaneamente diminuir o tempo de trabalho necessário e aumentar a concorrência entre os trabalhadores. Lebowitz conclui de forma eloquente ao dizer que "a condição necessária para a existência da mais valia relativa é a capacidade do capital enfraquecer os trabalhadores", condição necessária para a redução dos salários nominais (2010, p.144). A esse respeito, Fine (2009) observa que a luta de classe não se encontra no mesmo nível de abstração da análise da mais valia relativa. Como a extração de mais valia condiciona a luta de classe, esta somente pode ser introduzida após a análise da mais valia ter sido desenvolvida. Para ele, o grau de divisão surge como um conceito que salta a etapa necessária da análise teórica que deve ser desenvolvida antes da introdução da luta de classe. Ademais, argumenta ele, o grau de divisão entre os trabalhadores é diferente nos vários ramos da economia, e não há nenhum mecanismo capaz de homogeneizá-los, como ocorre, por exemplo, com outras categorias da economia política. 
Deve-se observar, no entanto, que Fine (2008) faz pouco uso dos capítulos 11, 12 e 13, nos quais Marx mostra que o processo de transformação da Cooperação à Manufatura e da Manufatura à Grande Indústria comporta simultaneamente o aumento da produtividade pelo qual se reduzem os valores das mercadorias e, ao mesmo tempo, uma contínua simplificação do trabalho. Desse modo, Marx procura mostrar que o valor da força de trabalho se reduz por dois motivos: $1^{\circ}$ Pela diminuição do custo de formação da força de trabalho devido à simplificação do trabalho e $2^{\circ}$ Pela diminuição do valor das mercadorias. Enquanto o valor da força de trabalho é reduzido por essas duas forças, o preço da força de trabalho é pressionado para baixo pelo processo de simplificação do trabalho, processo esse que aumenta o pool de trabalhadores disponíveis para o capital e, portanto, aumenta o grau de concorrência entre eles.

Este artigo argumenta que Lebowitz amalgama dois momentos distintos: o aumento da produtividade, que determina o grau máximo da mais valia relativa - análise que Marx empreende tomando como fixas as necessidades de consumo dos trabalhadores - e o grau efetivo da mais valia relativa, grau esse que depende da magnitude do ajuste do salário monetário entre o nível mínimo correspondente ao novo valor e o nível máximo que corresponde à manutenção dos salários nominais constantes. O primeiro processo poderia ser denominado de processo de determinação do valor da força de trabalho; o segundo processo seria o mecanismo de determinação do preço da força de trabalho. Este último apenas determina o grau de redução do preço da força de trabalho e, portanto, a partilha dos ganhos de produtividade entre trabalhadores e capitalistas. Os mecanismos de redução do valor e de determinação da partilha do aumento da produtividade pertencem a momentos distintos da análise e deveriam ser analisados separadamente. Para Lebowitz, o mecanismo de determinação do preço está implícito na natureza capitalista do progresso técnico, cujo objetivo é o controle do processo de trabalho e, portanto, o progressivo esvaziamento das condições de reação coletiva da classe trabalhadora. Este artigo argumenta que a determinação do valor da força de trabalho e a determinação do preço da força de trabalho são dois processos distintos, vale dizer, não há uma ligação imediata entre aumento da produtividade e redução do salário nominal, devido ao aumento do grau de divisão entre os trabalhadores, grau de divisão esse produzido pela natureza de classe do aumento da produtividade. 
É importante também observar que ao longo de sua discussão sobre o conceito de mais valia relativa, Marx não faz nenhuma menção ao aumento da produtividade na produção do material monetário, o ouro. Um aumento da produtividade na produção de ouro na mesma proporção do aumento da produtividade na produção das mercadorias que entram no consumo da força de trabalho traz a consequência de que nenhuma redução do salário monetário é necessária para que haja aumento da mais valia relativa. Ao contrário do caso analisado por Marx, quando a produtividade na produção de ouro aumenta na mesma proporção da produtividade geral, a mais valia relativa se efetiva ao seu grau máximo, mesmo sem qualquer redução do salário nominal. Resultado semelhante se obtém através da desvalorização do padrão de preço, como se verá adiante. A análise de possíveis vias de redução do valor da força de trabalho, independentemente da luta de classe, são apresentadas como alternativas à concepção de Lebowitz.

\section{Marx e a Mais Valia Relativa}

A mais valia relativa ocupa um lugar central na análise do capital empreendida por Marx. O estudo da mais valia relativa aparece nos Grundrisse (pp.333-344), nos Manuscritos e 1861-63 (pp.243-375) e finalmente n'O Capital, toda a seção IV, sobre A "Produção da Mais Valia Relativa". ${ }^{1}$ São centenas de páginas dedicadas a esse tema essencial para o entendimento do conceito de capital, conceito que Marx procura desenvolver antes de introduzir elementos relativos à interação dos capitais em concorrência.

A mais valia relativa permite uma contínua expansão do trabalho excedente, fato inédito se comparado aos modos de produção anteriores. Permite também superar a limitação que a extração de mais valia absoluta encontra na extensão da jornada de trabalho. De fato, é assim que ele ordena o pensamento nos Manuscritos, de 1861-63: "Admitamos, portanto, que a jornada de trabalho global tenha atingido seus limites normais.

1 As Teorias da Mais Valia, apesar do título, não discutem a mais valia relativa pela razão de que ali Marx analisa as teorias prévias da mais valia, teorias que ainda não apresentavam a forma relativa, mas apenas a absoluta. 
É somente então que se verá a tendência do capital a produzir mais valia, i.e., tempo de sobre-trabalho, nas suas modalidades particulares e características" (Marx 1979, 243).

\subsection{Distinções Fundamentais: Valor, Preço e Preço de Mercado da} Força de Trabalho

Marx define o valor da força de trabalho como o tempo de trabalho necessário para a produção das mercadorias que entram na reposição da capacidade de trabalho. Essas mercadorias se encontram no mercado pelos seus preços de produção. A força de trabalho não pode receber seu valor, isto é, a tradução em dinheiro do tempo de trabalho necessário, pois se as mercadorias de que necessita fossem produzidas em ramos de composições orgânicas maiores que a média, os preços dessas mercadorias estariam acima dos seus valores e a força e trabalho não poderia se reproduzir. A força de trabalho deve ser paga pelo seu preço de (re)produção, que é a soma dos preços de produção das mercadorias das quais necessita normalmente para viver. O preço de mercado da força de trabalho, por sua vez, é o preço decorrente do embate entre oferta e demanda de trabalho, assim como da capacidade organizativa das classes na luta pelos seus interesses materiais. $\mathrm{O}$ preço de mercado da força de trabalho tem como baliza de referência o preço de (re)produção da força de trabalho.

A presente análise, no entanto, assume que as mercadorias consumidas pela força de trabalho se originam de ramos de composição média - ou alternativamente que seus desvios em relação à média se anulam - e que, portanto, o preço da força de trabalho é igual à expressão direta do tempo de trabalho necessário em dinheiro, entendido como certa quantidade de ouro.

\subsection{Produtividade e Luta de Classe}

Existem dois mecanismos que devem ser separados quando se estuda a mais valia relativa. Um é lógico e pertence à análise da natureza do capital; o outro é histórico e diz respeito à luta de classe. O primeiro é o mecanismo da mais valia relativa. Esse mecanismo permite compreender como se determina o valor da força de trabalho. O segundo 
mecanismo diz respeito à luta de classe; esse mecanismo determina o preço da força de trabalho.

Esses dois mecanismos nos colocam uma dificuldade imediata. A divergência do preço da força de trabalho relativamente ao seu valor faz parte do processo de cristalização de um novo padrão de consumo, fato que sugere que o preço da força de trabalho faz parte do processo de modificação do valor da força de trabalho.

No caso das mercadorias ordinárias o preço oscila ao redor do valor. No caso da mercadoria força de trabalho, o novo padrão de consumo só pode se fixar através do exercício de um poder de compra que exceda o poder de compra anterior. Parece, então, que no caso da mercadoria força de trabalho, o preço age como determinante do valor, fato que, prima facie, contradiz a teoria do valor. Mas essa contradição é apenas aparente. A mercadoria força de trabalho, sendo uma mercadoria especial, sua reprodução contém uma dimensão moral-histórica. Essa dimensão moral-histórica só pode se fixar através da fixação de um poder de compra que comporte os novos valores de uso que se incorporam no consumo da força de trabalho à medida que aumenta a produtividade e a divisão social do trabalho que a acompanha.

Existem três mecanismos, a saber: o processo de diminuição do valor da força de trabalho; o processo de determinação do preço da força de trabalho; finalmente, a influência do preço da força de trabalho sobre a determinação do novo valor da força de trabalho, processo que se dá pela emergência de novas necessidades adicionadas à cesta de consumo dos trabalhadores. Este artigo se concentra exclusivamente sobre os dois primeiros processos.

Antes, porém, de adentrarmos a análise, é preciso dirimir uma possível fonte de confusão. Normalmente se pensa que se os salários não caem com o aumento da produtividade, os benefícios do progresso técnico são totalmente absorvidos pelos trabalhadores. Na verdade, ambas as classes absorvem os benefícios da maior produtividade, tendo em vista que o mesmo salário e a mesma mais valia podem comprar uma quantidade maior de produtos. Isso pode ser ilustrado facilmente, uma vez que tenhamos em mente que o aumento da produtividade não aumenta a massa de valor, mas apenas a quantidade de valores de uso produzidos. Suponhamos uma jornada de 
12 horas que se materializa numa quantidade de $10 \mathrm{~kg}$ de feijão, na qual o valor da força de trabalho ou o tempo de trabalho necessário, TTN, corresponde a 6 horas e a mais valia ou o tempo de trabalho excedente, TTE, corresponde a 6 horas, como segue:

TTN

6 horas
TTE

6 horas

Suponhamos ainda que 12 horas representem em termos de dinheiro 120 gramas de ouro. Se fizermos

20 gramas de ouro $=1$ xelim

então, temos o valor, o preço em dinheiro e o preço em termos do padrão de preço $^{2}$ da força de trabalho, como segue:

Tabela 1 - Valor, preço-dinheiro e preço-padrão da força de trabalho

\begin{tabular}{|c|c|c|}
\hline $\begin{array}{c}\text { Valor da força de trabalho ou Tempo } \\
\text { de trabalho necessário }\end{array}$ & Preço-dinheiro da força de trabalho & Preço-padrão da força de trabalho \\
\hline 6 horas & 60 gramas de ouro & 3 xelins \\
\hline
\end{tabular}

O preço da força de trabalho é 3 xelins em termos do padrão de preço, em conformidade com algumas ilustrações do próprio Marx. Isso quer dizer que tanto a mais valia quanto o valor da força de trabalho correspondem a 3 xelins cada um. Se a produtividade dobrasse, teríamos uma produção de $20 \mathrm{~kg}$ de feijão, mas o valor total produzido continuaria sendo equivalente a 6 xelins, igualmente divididos entre capitalistas e trabalhadores. Porém, agora ambas as classes poderiam comprar o dobro de valores de uso, ou seja, $10 \mathrm{~kg}$ de feijão cada uma. Assim fica claro que o aumento da produtividade não seguido de uma redução dos salários nominais não implica que todo o ganho de produtividade seja absorvido pelos trabalhadores. Como mostra o exemplo, ambas as classes teriam benefícios proporcionalmente iguais.

2 Para uma discussão dessas categorias, veja-se Germer (1997), texto no qual o autor mostra que os preços expressos no padrão de preço podem mudar sem que mudem os preços-dinheiro das mercadorias, isto é, os preços expressos na quantidade da matéria que mede o valor. 


\subsection{O Mecanismo de Determinação do Valor da Força de Trabalho}

Para definir o valor da força de trabalho, Marx precisou definir como se reproduz a força de trabalho. Ela se reproduz pelo consumo e, portanto, requer uma determinada quantidade de meios de subsistência, meios esses que são conhecidos em cada lugar, em cada período histórico. Para definir o valor da força de trabalho era preciso primeiramente fixar a variedade e a quantidade dos meios de subsistência que entram na reprodução da força de trabalho. Somente essa fixação inicial permite mostrar que a mais valia relativa não pode surgir senão de uma redução do valor desses meios de subsistência. Esse procedimento permite também compreender que o aumento do consumo dos trabalhadores e a diminuição do valor da força de trabalho são compatíveis.

O aumento da produtividade faz baixar o valor daquele conjunto de meios de subsistência e, portanto, o valor da força de trabalho "desde que a capacidade de trabalho seja sempre vendida ao seu valor" (Marx 1979 p. 245). Isso porque é necessário menos tempo de trabalho para a sua reposição.

Note-se que aqui, para explicar a mais valia relativa Marx considera a hipótese de que a força de trabalho seja vendida ao seu valor. Como não há ainda uma análise dinâmica da transformação do padrão de consumo da força de trabalho, o valor da força de trabalho deve refletir o valor da cesta fixa.

A primeira dificuldade é que Marx apresenta a tendência do capital a aumentar a mais valia relativa independentemente da percepção dos agentes capitalistas envolvidos, como obra do capital e não dos indivíduos. Isso é necessário, pois os indivíduos não podem expressar o que buscam em termos da engrenagem íntima das relações sociais nas quais estão submersos, pela simples razão de que a natureza dessas relações não se revela explicitamente para eles. Ao contrário, as relações aparentes são as que se apresentam aos sentidos e essas se expressam como preços, custos, etc. Como resolve Marx a relação entre a tendência inerente ao capital de aumentar a mais valia relativa e a atividade prática do capitalista individual ? Vejamos: 
Toda dificuldade advém do fato de que quando o capitalista individual aumenta a produtividade, ele não pensa em diminuir o tempo de trabalho necessário, mas pensa em vender acima do seu valor - de elevá-la acima do tempo de trabalho médio. Mas desse tempo de trabalho mais elevado o salário representa uma proporção menor, ou seja, o tempo de trabalho excedente aumenta, ainda que esse aumento se realize indiretamente através da venda acima do valor. (Marx, 1979, p. 250)

Assim, enquanto o capitalista individual procura controlar o processo de trabalho e diminuir os custos através da racionalização do processo produtivo, está simultaneamente executando a natureza íntima do capital que é a de aumentar continuamente a mais valia relativa.

Marx mantém exatamente o mesmo procedimento no capítulo intitulado "Conceito de Mais Valia Relativa" do primeiro volume d'O Capital. O capitalista individual que introduz um método de produção que aumenta a produtividade do trabalho obtém mais valia relativa independentemente da diminuição do valor da força de trabalho através da venda de suas mercadorias acima do seu valor individual, fazendo com que diminua à proporção que os salários representam nesse valor aumentado. Não deveria Marx aplicar ao caso do capitalista individual o mesmo procedimento que aplicou quando da análise do aumento da produtividade da economia no seu conjunto? Se assim fosse, não poderíamos considerar o caso do capitalista que utiliza um método mais produtivo como sendo um caso de produção de maior massa de valor. $\mathrm{Na}$ verdade, produz a mesma massa de valor que antes. A capacidade de vender abaixo do valor de mercado e acima do seu valor individual apenas indica a existência de uma transferência de valor. É verdade que os salários representam uma proporção menor da soma de lucros e salários, mas isso em virtude da transferência de valor e não da maior produção de valor.

Seja como for, a sequência de determinação do valor da força de trabalho vai da cesta de consumo para a soma do valor dos elementos dessa cesta. Como o valor é tempo de trabalho, o valor da força de trabalho é o tempo de trabalho necessário para produzir os elementos contidos nessa cesta: 


\section{Meios de subsistência necessários \\ $\downarrow$ \\ Soma dos valores desses meios de subsistência \\ Valor da Força de Trabalho}

Mas o valor da força de trabalho é equivalente ao valor dos elementos da cesta ou equivalente ao preço dos elementos da cesta? Sabemos que os preços gravitam ao redor dos preços de produção. A força de trabalho tem que comprar os seus meios de subsistência aos preços disponíveis no mercado. Seria, então, melhor dizer que o valor da força de trabalho deve ser a soma dos preços de produção das mercadorias que constituem a cesta de consumo normal dos trabalhadores. A aparente contradição advém do fato de que o valor da força de trabalho é definido em termos de tempo de trabalho, enquanto sua reprodução pressupõe um poder de compra capaz de refazer sua capacidade de trabalho e, portanto, capaz de comprar as mercadorias aos preços vigentes. Imaginemos por alguns instantes a possibilidade de que os meios de subsistência da classe trabalhadora sejam produzidos em ramos que operam com composições orgânicas do capital acima da média.

Nesse caso, a expressão em dinheiro do valor da força de trabalho estaria sistematicamente abaixo do preço de produção dos meios de subsistência, já que naqueles ramos os preços de produção estariam sistematicamente acima dos valores. E vice-versa se os meios de consumo da classe trabalhadora se originassem de ramos com composição orgânica abaixo da média. Nesse caso, a expressão em dinheiro do valor da força de trabalho se situaria sistematicamente acima do preço de produção dos meios de subsistência. Somente a coincidência de que os meios de subsistência produzidos em ramos com composição orgânica abaixo da média fossem compensados pelos meios de subsistência provenientes de ramos com composição acima da média, somente nesse caso o preço da força de trabalho seria igual ao valor. Para efeitos da continuidade da exposição essa é a última circunstância que tomaremos como reguladora do valor da força de trabalho, uma vez que as questões pertinentes ao presente artigo não requerem maiores digressões sobre a dificuldade apresentada acima. 
A variação dos preços ao redor dos preços de produção não requer que o salário se ajuste continuamente. De fato, não poderia fazê-lo, sob pena de uma constante modificação dos salários. Por que então designá-la de valor da força de trabalho e não de preço da força de trabalho? Ora, poderíamos designá-la de preço de produção da força de trabalho, mas isso seria inadequado, pois na produção da força de trabalho não entra o lucro médio além dos seus custos. No seu custo já estão incluídos o lucro médio de todas as mercadorias que ela consome. Denominá-la simplesmente de preço tornaria confusa a análise das variações do preço ao redor de seu valor, ou seu custo de reprodução.

\subsection{Luta de Classe: O Mecanismo da Determinação do Preço da Força de Trabalho}

Ao longo de suas discussões, Marx assume que o salário cai quando os valores caem, procedimento necessário para mostrar como pode ser produzida a mais valia relativa. Assim, nos Grundrisse, após considerar uma duplicação da produtividade do trabalho, ele conclui que "o valor de troca da capacidade de trabalho cai pela metade porque metade do tempo de trabalho original gera o mesmo valor de uso" (Marx 1973, p. 344). Mas também é certo que Marx concebia essa redução do salário nominal como algo não automático, uma vez que sugeria a possibilidade de que tanto a mais valia quanto o salário real crescessem simultaneamente, fenômeno que só é possível precisamente porque não existe um mecanismo automático de redução dos salários para o nível do novo valor dado pela maior produtividade do trabalho.

Ademais, o aumento da mais valia relativa não significa que as condições de vida dos trabalhadores permaneçam iguais, i.e., que sigam consumindo os mesmos produtos do ponto de vista quantitativo e qualitativo. Ao contrário, Marx apresenta um exemplo no qual uma jornada de 12 horas é primeiramente dividida em 10 horas de trabalho necessário e 2 horas de trabalho excedente, como segue:

TTN TTE

10 horas 2horas 
Suponhamos - para efeitos de homogeneização com os exemplos a serem apresentados posteriormente - que cada hora corresponda a $1 / 2$ xelim. Desse modo, o valor inicial da força de trabalho é 5 xelins e a mais valia é 1 xelim. Em seguida, suponhamos que a produtividade dobre. $\mathrm{O}$ valor da força de trabalho cairia para 5 horas, o equivalente a $2^{1 / 2}$ xelins. Se o salário caísse para 3 ao invés de $2 \frac{1}{2} 2$ xelins, então "suas condições de vida melhorariam na mesma proporção de que se ele trabalhasse as doze horas para si nas condições de produtividade anterior" (Marx 1979, p.255).

É claro então que Marx não tinha dúvidas quanto ao fato de que o nível de vida dos trabalhadores poderia mudar mesmo com a mais valia crescendo continuamente, como de fato é explícito a respeito:

A mais valia relativa pode crescer continuamente, o valor da força de trabalho pode diminuir continuamente e com ele o valor do salário médio, enquanto que a esfera de meios de subsistência e, portanto, das satisfações da vida do trabalhador podem se alargar continuamente. (Marx 1979, 255)

No capítulo XV do volume primeiro d'O Capital, cujo tema é a variação da grandeza relativa do preço da força de trabalho e da mais valia, Marx apontou para a possibilidade de que tanto a mais valia quanto o padrão de consumo da classe trabalhadora subissem como consequência do aumento da produtividade. Para vermos como isso se dá, consideremos o exemplo no qual uma jornada de 12 horas dividida em 8 horas de tempo de trabalho necessário e 4 horas de tempo de trabalho excedente, no conjunto da qual se produz um valor de 6 xelins:

\section{TTN TTE}

$\begin{array}{ccc}8 \text { horas } & & 4 \text { horas } \\ \downarrow & \downarrow \\ 4 \text { xelins } & & 2 \text { xelins }\end{array}$


Se a produtividade reduz o TTN para 6 horas, o valor da força de trabalho cai para 3 xelins. Teríamos a seguinte representação:

TTN

6 horas

$\downarrow$

3 xelins
TTE

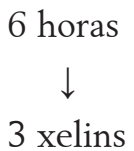

É nesse momento que Marx introduz a luta de classe para determinar a fixação do preço da força de trabalho:

o grau da queda, cujo limite são os 3 xelins, depende do peso relativo que a pressão do capital, de um lado, e a resistência do trabalhador, de outro, jogam no prato da balança. (idem, p. 115).

Suponhamos o mesmo exemplo. Se a produtividade do trabalho dobrasse novamente, o valor da força de trabalho cairia para 1 1/2 xelins. A respeito desse exemplo, Marx faz o seguinte comentário:

Se o preço da força de trabalho caísse não até o limite mínimo de 1 1/2 xelim dado pelo seu novo valor mas para 2 xelins e 10 pence, 2 xelins e 6 pence etc., esse preço decrescente representaria ainda uma crescente massa de meios de subsistência. O preço da força de trabalho poderia assim cair continuamente, ao crescer a força produtiva do trabalho, com crescimento simultâneo contínuo da massa dos meios de subsistência do trabalhador. (Marx 1985, v.II, p.115-116)

Esse fenômeno, no entanto, requer que os salários nominais recuem para um nível entre o antigo valor da força de trabalho e o novo valor da força de trabalho resultante do barateamento das mercadorias. Isso significa que deveria haver um mecanismo pelo qual a redução 
dos salários resultasse num preço da força de trabalho acima do novo valor, caso no qual aumentaria o padrão de consumo da força de trabalho, juntamente com o aumento da mais valia. É a tentativa de prover tal mecanismo que levou Lebowitz a introduzir a luta de classe não como fenômeno da determinação do preço da força de trabalho, mas como fenômeno da determinação da mais valia relativa, tout court.

Este artigo, ao contrário, procura separar os dois momentos que Lebowitz apresenta glosados. O primeiro refere-se à determinação do valor da força de trabalho; o segundo diz respeito à determinação do preço da força de trabalho:

\section{$1^{\circ}$. Momento:}

$\uparrow$ produtividade $\rightarrow$ grau máximo de mais valia relativa $\rightarrow$ determina novo valor $F T$

\section{$2^{\circ}$. Momento:}

$\downarrow$ salário nominal $\rightarrow$ grau efetivo de mais valia relativa $\rightarrow$ determina preço da FT

Num primeiro momento, o aumento da produtividade e o consequente barateamento das mercadorias determinam o grau máximo que pode alcançar a mais valia relativa. Esse primeiro momento constitui as novas condições a partir das quais se deve configurar um novo salário nominal. O processo de determinação desse novo salário nominal forma, então, o segundo momento. Em termos gráficos, esse duplo processo poderia ser representado assim:

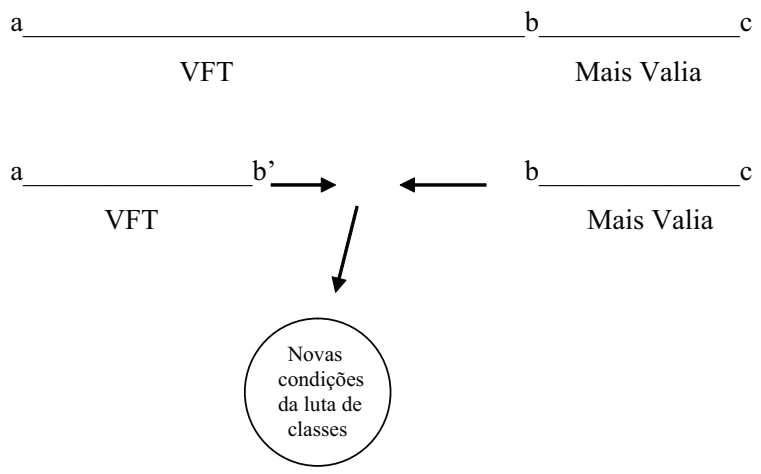


O gráfico mostra que a determinação de um novo valor da força de trabalho, oriundo da diminuição do valor das mercadorias que compõem sua cesta de consumo, abre um espaço para o exercício do conflito entre capital e trabalho. A redução do valor da força de trabalho de $a b$ para $a b^{\prime}$ abre um campo de possível aumento da mais valia de relativa, cuja dimensão máxima é dada pelo segmento $b^{\prime} b$. É o resultado líquido desse conflito, seu efeito em termos de fixação de um novo salário nominal, o processo de que trata a determinação do preço da força de trabalho. Essa determinação resulta dos condicionantes do mercado de trabalho, notadamente o balanço entre oferta e demanda de trabalho como determinante do grau de concorrência entre os trabalhadores, assim como o grau de organização sindical da classe. Por isso esse processo pertence a um nível da análise distinto, nível esse que tem como ponto de partida as novas condições postas pelo aumento da produtividade, mas que não pode resolver-se no mesmo horizonte temporal.

\section{Mais Valia Relativa e Salários Nominais}

Ao longo de sua discussão sobre a mais valia relativa, Marx supôs a produtividade do trabalho na produção do ouro como sendo constante. Deve-se isso ao fato de que Marx antevia limites intransponíveis ao desenvolvimento da produtividade na produção do material monetário, ou tratar-se-ia de um procedimento metodológico que visava concentrar atenção para o fato de que os salários nominais precisam cair para que se efetive a mais valia relativa? Para lidar com a possibilidade de crescimento da produtividade na produção de ouro, utilizaremos alguns exemplos numéricos que permitam ilustrar a necessidade ou não de rebaixamento dos salários nominais para a efetivação da mais valia relativa.

Diferentemente das outras mercadorias, a força de trabalho é sui generis no sentido de que a sua desvalorização nominal não é automática, mas ao contrário, por se materializar nos próprios indivíduos, encontra resistência contrária àquela redução na ação subjetiva da força de trabalho. Suponhamos que a força de trabalho logre manter seu preço valorizado relativamente aos meios de produção, cujo preço reflete a redução de valor mais ou menos mecanicamente. Esse mecanismo de valorização relativa do preço da força de trabalho em 
comparação com o preço dos meios de produção põe em moto um mecanismo de substituição de trabalho por máquinas sempre que aquela valorização relativa torne o custo de depreciação por unidade de produto mais barato do que o custo unitário salarial durante um período de tempo correspondente à vida produtiva da máquina.

Esse processo de mecanização se desenvolve enquanto permanece aquela diferença em favor da máquina de modo que somente quando a mecanização é tão profunda que finalmente torna o trabalho redundante numa escala que desvaloriza o preço da força de trabalho, somente então o processo desaparece. Esse mecanismo, porém, deixaria a efetivação da mais valia relativa para a dimensão do longo prazo, fato que o torna problemático como mecanismo explicativo.

A seguir examinaremos quatro casos distintos. Define-se, para efeitos classificatórios, como independente da luta de classe, a mais valia relativa que se obtém sem recurso a qualquer modificação no salário nominal. Com base nessa definição, apresentamos primeiramente os dois casos que implicam luta de classe, seja porque o salário tem que cair para que se obtenha mais valia relativa, seja porque os salários precisam aumentar para que a força de trabalho receba o equivalente ao seu valor. Os dois últimos casos logram realizar a mais valia relativa ao grau correspondente ao novo valor da força de trabalho independentemente da luta de classe.

\section{Condições para a Mais Valia Relativa que Implicam Luta de Classe}

\section{Caso 1 - Produtividade na Produção de Ouro Constante, Produtivi- dade Crescente nos Ramos que Produzem os Meios de Subsistência da Força de Trabalho}

A Tabela 2 abaixo descreve os dados que tomamos como ponto de partida da análise. O padrão de preço, entendido como a fixação de uma unidade de medida que mede as quantidades de ouro, é fixado como sendo

$$
1 \text { xelim }=20 \text { gramas de ouro }
$$


Assim, as quantidades imaginárias de ouro que medem o valor das mercadorias são por sua vez medidas em termos desse padrão. Por exemplo, se uma mercadoria vale 25 gramas de ouro seu preço-padrão é de 1,25 xelins.

Tabela 2 - Cesta de consumo fixa e valor da força de trabalho

\begin{tabular}{|c|c|c|c|}
\hline Cesta de consumo fixa & $\begin{array}{c}\text { Valor da força de trabalho } \\
\text { ou tempo de trabalho } \\
\text { necessário }\end{array}$ & $\begin{array}{c}\text { Preço-dinheiro da força de } \\
\text { trabalho }\end{array}$ & $\begin{array}{c}\text { Preço-padrão da força de } \\
\text { trabalho }\end{array}$ \\
\hline $\begin{array}{c}\text { Meios de subsistência da } \\
\text { força de trabalho }\end{array}$ & 6 horas & 60 gramas de ouro & 3 xelins \\
\hline
\end{tabular}

Se o valor do ouro é constante e a produtividade dobra nos ramos que produzem os meios e subsistência da força de trabalho, então obtemos o seguinte resultado:

\begin{tabular}{|c|c|c|c|}
\hline Cesta de consumo fixa & $\begin{array}{c}\text { Valor da força de trabalho } \\
\text { ou tempo de trabalho } \\
\text { necessário }\end{array}$ & $\begin{array}{c}\text { Preço-dinheiro da força } \\
\text { de trabalho }\end{array}$ & $\begin{array}{c}\text { Preço-padrão da força } \\
\text { de trabalho }\end{array}$ \\
\hline $\begin{array}{c}\text { Meios de subsistência da } \\
\text { força de trabalho }\end{array}$ & 3 horas & 30 gramas de ouro & $1 \frac{1 / 2 \text { xelins }}{}$ \\
\hline
\end{tabular}

O novo valor da força e trabalho corresponde a $1^{1 / 2}$ xelim. Se o preço da força de trabalho permanecer em 3 xelins, não haverá mais valia relativa, apenas a mesma mais valia materializada em mais valores de uso, como explicado anteriormente. Para que haja um valor maior apropriado pelo capital, é preciso que o preço da força de trabalho diminua para representar uma fração menor do que 6 horas. O preço da força de trabalho, $P_{F T}$, teria que cair não necessariamente para $1 \frac{1}{2}$ xelim, mas para um nível que obedecesse as seguintes desigualdades:

$$
11 \frac{1}{2} \text { xelim }<P_{F T}<3 \text { xelins }
$$

em que $P_{F T}$ é o preço da força de trabalho. Qualquer nível no interior dessa desigualdade implica que o salário se elevaria acima do novo valor da força de trabalho, mas abaixo do valor anterior. 
Caso 2 - Aumento da Produtividade na Produção do Ouro maior do que o Aumento da Produtividade na Produção das Mercadorias que Reproduzem a Força de Trabalho. Exemplo: Dobra Produtividade na Mineração enquanto o Tempo para Produzir os meios de Subsistência da Força de Trabalho cai de 6 horas para 4 Horas

Tomemos como ponto de partida os dados da Tabela 2, apresentada no Caso 1, acima. Com a duplicação da produtividade na mineração de ouro, passamos a obter 120 gramas de ouro em 6 horas de traba1ho. Por outro lado, o tempo de trabalho necessário correspondente à produção dos meios de subsistência da força de trabalho cai de 6 horas para 4 horas. Mantendo-se o padrão de preços sem alteração teríamos:

\begin{tabular}{|c|c|c|c|}
\hline Cesta de consumo fixa & $\begin{array}{c}\text { Valor da força de trabalho } \\
\text { ou Tempo de trabalho } \\
\text { necessário }\end{array}$ & $\begin{array}{c}\text { Preço-dinheiro da força } \\
\text { de trabalho }\end{array}$ & $\begin{array}{c}\text { Preço-padrão da força } \\
\text { de trabalho }\end{array}$ \\
\hline $\begin{array}{c}\text { Meios de subsistência da } \\
\text { força de trabalho }\end{array}$ & 4 horas & 80 gramas de ouro & 4 xelins \\
\hline
\end{tabular}

O preço-dinheiro da cesta de consumo se elevou para 80 gramas de ouro, enquanto o preço-padrão da força de trabalho subiu para 4 xelins. Isso significa que para comprar os seus meios de subsistência, a força de trabalho deveria receber agora 4 xelins, um xelim a mais do que antes. Ou seja, o valor produzido na jornada é igual a 240 gramas de ouro. Para comprar seus meios de subsistência, a força de trabalho precisa ganhar 80 gramas de ouro. Se o padrão de preço não mudou, 1 xelim continua sendo 20 gramas de ouro. Com os seus 3 xelins de salário, ou seja, 60 gramas de ouro, o padrão de vida dos trabalhadores se reduz em $1 / 4$. Se o salário não logra aumentar para 4 xelins, teríamos simultaneamente aumento da mais valia relativa e transformação de uma parte do fundo de consumo da força de trabalho em fundo de acumulação, transformação essa advinda da redução do preço da força de trabalho abaixo do seu valor. Este último fenômeno é descartado por Marx, pois não explica a mais valia relativa em condições nas quais a força de trabalho pode se reproduzir normalmente. Portanto, aqui assumimos que os trabalhadores logram aumentar os salários para 4 xelins. 
Para que a força de trabalho receba o equivalente ao seu custo de reprodução, o salário nominal teria que aumentar $1 / 3$, uma vez que os gêneros de consumo dos trabalhadores teriam aumentado de $1 / 3$ também, seja em preço-dinheiro, seja em preço-padrão como resultado da desvalorização do ouro. Esse é o caso de inflação na teoria de Marx que pode advir da desvalorização do dinheiro metal.

Mecanismo análogo poderia ocorrer se ao invés de aumentar a produtividade na produção de ouro se emitissem símbolos de valor em excesso relativamente ao dinheiro metal que supostamente deveriam substituir na circulação, caso que será analisado adiante.

\section{Conclusões sobre Casos 1 e 2}

Os dois casos apresentados acima implicam luta de classe, pois os salários nominais precisam mudar. No primeiro caso, para que ocorra mais valia relativa, os salários nominais precisam ser rebaixados, fato que implica um ataque patronal ao nível dos salários existentes.

O caso dois tem como consequência uma abrupta queda no poder de compra dos salários devido à inflação resultante da desvalorização do ouro. Para obter o equivalente ao seu valor, a força de trabalho deveria ser capaz de recompor o poder de compra dos seus salários através de um reajuste dos salários nominais ao novo nível de preços correspondente à desvalorização do ouro e ao novo preço-padrão da força de trabalho.

\section{Condições para a Mais Valia Relativa Independentemente da Luta de Classe}

Caso 3 - Com Aumento da Produtividade na Produção do Ouro Equivalente ao Aumento da Produtividade na Produção das Mercadorias que Reproduzem a Força de Trabalho

Nesse caso os salários monetários podem permanecer constantes. Com o mesmo salário que antes, os trabalhadores obterão exatamente a mesma cesta de consumo que obtinham antes do aumento da 
produtividade. Isso ocorre porque a desvalorização do dinheiro faz com que a mesma massa monetária de antes possa comprar a mesma cesta igualmente desvalorizada:

Tempo de trabalho socialmente necessário para produzir a cesta de consumo $=3$ horas de trabalho

Tempo de trabalho socialmente necessário para produzir 60 gramas de ouro $=3$ horas de trabalho

\begin{tabular}{|c|c|c|c|}
\hline Cesta de consumo fixa & $\begin{array}{c}\text { Valor da força de trabalho } \\
\text { ou Tempo de trabalho } \\
\text { necessário }\end{array}$ & $\begin{array}{c}\text { Preço-dinheiro da força de } \\
\text { trabalho }\end{array}$ & $\begin{array}{c}\text { Preço-padrão da força de } \\
\text { trabalho }\end{array}$ \\
\hline $\begin{array}{c}\text { Meios de subsistência da } \\
\text { força de trabalho }\end{array}$ & 3 horas & 60 gramas de ouro & 3 xelins \\
\hline
\end{tabular}

Não tendo mudado o padrão de preço, 60 gramas de ouro continuam se denominando 3 xelins. Ao receber 3 xelins, a força de trabalho continua comprando exatamente a mesma cesta de consumo. O salário nominal pode permanecer constante e mesmo assim se produz mais valia na forma relativa.

Caso 4 - Desvalorização do Papel-Moeda na mesma Proporção da Desvalorização das Mercadorias, o Valor do Ouro Mantendo-se Constante

Mas como conceber a inflação atual na qual aparentemente a produtividade na mineração de ouro não parece ter papel algum? E mais: qual seria a relação orgânica entre aumento da produtividade e inflação, prima facie, um paradoxo?

Suponhamos que os xelins-ouro se depositem nos bancos e em seu lugar se emita papel-moeda xelim. Descrevamos nosso ponto de partida como:

60 gramas de ouro $=3$ xelins 
Suponhamos agora que a quantidade desse papel-moeda exceda as necessidades da circulação, ou seja, exceda em dobro o volume de ouro capaz de circular as mercadorias. A emissão em excesso desvaloriza o papel-moeda em termos de ouro, obrigando a autoridade monetária a desvalorizar o padrão de preço. Descrevemos a seguir o mecanismo desse processo.

Primeiramente o padrão de preço continua estabelecido legalmente, como antes, à razão de

\section{0 gramas de ouro $=1$ xelim}

porém, já não se consegue obter 1 xelim ouro em troca de 1 xelim papel. Como isso provoca uma tentativa de trocar papel por ouro, a autoridade monetária se vê obrigada a desvalorizar o padrão de preço que no nosso exemplo deveria ser agora fixado a

$$
10 \text { gramas de ouro }=1 \text { xelim }
$$

Se a produtividade na produção das mercadorias que fazem parte do consumo da força de trabalho tivesse igualmente dobrado teríamos então o seguinte resultado:

Meios de subsistência necessários à força de trabalho $=3$ horas de trabalho

Meios de subsistência necessários à força de trabalho $=30$ gramas de ouro

Meios de subsistência necessários à força de trabalho $=3$ xelins 
O preço dos meios de subsistência continua 3 xelins, mas 3 xelins representam agora apenas $1 / 4$ da jornada de trabalho:

\begin{tabular}{|c|c|}
\hline VFT & mais valia \\
\hline 3 xelins & 9 xelins \\
\hline$\downarrow$ & $\downarrow$ \\
\hline 30 gramas & 90 gramas \\
\hline de ouro & de ouro \\
\hline
\end{tabular}

Portanto, apesar de o preço da força de trabalho ter-se mantido em 3 xelins, seu valor teria caído para 30 gramas de ouro ou 3 horas de trabalho, enquanto a mais valia teria aumentado para 9 horas ou 90 gramas de ouro.

A desvalorização do papel-moeda permite que se efetive a mais valia relativa oriunda de um aumento da produtividade sem a necessidade de desvalorização do preço da força de trabalho em termos do padrão de preço. A mudança no padrão de preço pelo qual agora 30 gramas de ouro são equivalentes a 3 xelins implica que a mais valia relativa é compatível com a manutenção do salário nominal expresso em termos do padrão de preço.

\section{Conclusões}

Lebowitz (2010 p.132) sugere que ao abrir-se a possibilidade de uma cesta de consumo variável, a explicação da mais valia relativa se torna inadequada. Se a coesão de classe dos trabalhadores fosse capaz de manter os salários nominais constantes, então, o aumento de produtividade não se traduziria em mais valia relativa. Para ele, a luta de classe faz parte da teoria da determinação da mais valia relativa, pois somente através da luta de classe podemos saber o que vai acontecer com os salários nominais. Desse modo, a própria tecnologia deve ser entendida como um instrumento da luta de classe. 
Para ele, a tecnologia é concebida para que os ganhos de produtividade possam ser absorvidos pelo capital; é desenhada para dividir os trabalhadores. O progresso técnico diminui o valor das mercadorias e aumenta o grau de divisão entre os trabalhadores, fato que permite fazer com que os salários nominais caiam. Se assim não fosse, os trabalhadores acabariam absorvendo os frutos da maior produtividade na forma de uma cesta de consumo maior.

Fine (2009) respondeu a Lebowitz argumentando que a luta de classe se situa a um nível de análise mais concreto, e que o mecanismo da mais valia relativa pertence a um nível de abstração mais alto, anterior à análise da luta de classe. Por isso procurou fazer uma crítica do conceito de grau de divisão entre os trabalhadores. No entanto, sua crítica (2008) transforma tudo em particularidade e complexidade, do que resulta que nenhuma norma ou média é possível: os salários são gastos de acordo com cada um; cada mercadoria entra de forma diferente no consumo de cada estrato da força de trabalho.

Toda essa diversidade é mobilizada para combater o conceito de grau de divisão entre os trabalhadores como categoria agregada capaz de explicar o estado da luta de classe e as suas resultantes em termos de salário e a mais valia. Para ele, o processo de divisão dos ganhos de produtividade não pode ser reduzido a uma simples variável como, por exemplo, o grau de divisão proposto por Lebowitz. Fine levanta questões importantes (2008, p. 109), mas as utiliza com o objetivo de obstaculizar a análise teórica agregada. Como se determina a cesta de consumo? Como muda? Como lidar com a diversidade de consumo já que os trabalhadores recebem em dinheiro e não em mercadorias?

Ora, nenhum sociólogo hesitaria em propor que os indivíduos consomem aquilo que os torna iguais aos outros, ainda que o conjunto de mercadorias disponíveis se apresente como um leque aberto à personalização do consumo. Desse modo, a cesta se estabelece pela socialização baseada na produção generalizada de mercadorias. Sobre as mudanças na composição da cesta, joga um papel fundamental o aumento da produtividade em conexão com os desvios entre preço e valor da força de trabalho, que se originam da redução dos salários nominais que deixam margem para o alargamento das necessidades de consumo. 
O argumento básico de Lebowitz é que não se pode explicar a mais valia relativa sem introduzir a luta de classe. A mais valia relativa depende da redução dos salários nominais. Somente a introdução de uma tecnologia que enfraqueça a capacidade de resistência dos trabalhadores é capaz de permitir uma redução dos salários nominais.

É verdade que a variação dos salários depende do peso relativo do desemprego no emprego total. A mudança na razão entre o montante de desempregados e a parte ocupada da força de trabalho constitui a variável determinante que as classes sociais "jogam no prato da balança". Como a teoria de Marx projeta a necessária formação de uma superpopulação relativa crescente, parece factível que o mesmo processo que aumenta a produtividade do trabalho conduza a uma redução dos salários nominais, ainda que não como fenômeno imediato.

No entanto, a redução dos salários nominais não é estritamente necessária para explicar a existência de mais valia relativa. Procuramos, neste artigo, analisar possíveis condições para a efetivação da mais valia relativa independentemente de considerações sobre a luta de classe. Isso porque a luta de classe se engaja no terreno produzido pelo aumento da produtividade como um dos seus condicionantes principais. A análise prévia desses condicionantes é necessária. Os casos 3 e 4 apresentam possibilidades de realização de mais valia relativa sem a necessidade de redução dos salários nominais e, portanto, independentemente da luta de classe. Ademais, o efeito do grau de divisão entre os trabalhadores sobre os salários não é um fator concomitante ao aumento da produtividade, mas uma variável produzida pelo aumento da produtividade que condiciona a variação no preço da força de trabalho num horizonte temporal diferente do contínuo aumento da produtividade. 


\section{Referências}

FINE, Ben. Financialisation, the value of labour power, the degree of separation, and exploitation by banking. SOAS, Summer Seminar Series, April 30 ${ }^{\text {th }}, 2009$, mimeo.

FINE, Ben. Debating Lebowitz: is class conflict the moral and historical element in the value of labour-power? Historical Materialism, 16, 3, p. 105-14, 2008.

GERMER, Claus M. Dinheiro e dinheiro de crédito no capitalismo avançado. Ensaios FEE, 22(1): 205-228, 2001.

LEBOWITZ, Michael. Trapped inside the box? Five questions for Ben Fine. Historical Materialism 18, p. 131-149, 2010.

LEBOWITZ, Michael. Beyond Capital. Marx's Political Economy of the Working Class. New York: Palgrave Macmillan, 2003.

MARX, Karl. Manuscrits de 1861-1863. Cahiers I a V. Paris: Editions Sociales, 1979.

Marx, Karl. Grundrisse. Foundations of the Critique of Political Economy. New York: Penguin Books, 1993.

MARX, Karl. O Capital. Critica da Economia Política. São Paulo: Abril S.A. Cultural, volume I, 1985. 